\section{PHARMACOVIGILANCE OF QUALITY DEVIATIONS IN THE PUBLIC HEALTHCARE SYSTEM}

Carolina Resende Bitencourt ${ }^{1}$

Cristiane Aparecida

Menezes de Pádua ${ }^{2}$

Paula Lana de Miranda Drummond ${ }^{1}$

Edson Perini ${ }^{3}$

\title{
ABSTRACT
}

Drug quality deviation (DQD) is the disagreement with the parameters at the registration with after commercialization step. Pharmacovigilance programs should be notified of DQD to ensure drug efficacy and support patient safety.

Objective: To describe DQD from public healthcare system and its impact on the pharmaceutical service.

Methods: Descriptive analysis of DQD recorded at Belo Horizonte primary and secondary care facilities, from April to September 2016. Variables: Type of DQD, pharmaceutical product, therapeutic class, notifying health unit, risk classification, and reply of DQD notification. This analysis was described by measures of central tendency and dispersion.

Results: 329DQD in 271 notifications were recorded leading to a loss of 9,311 preparations, representing on average $0.2 \%$ of the purchased lot. Most DQD were recorded at the primary health care level in solid preparations. Drug-related problems included deviations in package content (47\%), package integrity (26\%), label (5\%), and pharmaceutical product itself (22\%). Anti-infectives for systemic use (21\%) and nervous system drugs (20,3\%) were the main therapeutical classes. Approximately $70 \%$ of the DQD were classified as of intermediate risk. Drug suppliers replied $83.6 \%$ of notifications. No notification has been completely analyzed by the sanitary surveillance.

Conclusions: Pharmacovigilance is an important tool to minimize potential harm to the patient, since it prevents inappropriate medications from being made available for dispensing. DQD management also helps to minimize financial losses. The strengthening of this activity in all healthcare services also contributes to regulatory actions at the national level.

Key Words: Quality deviation, pharmacovigilance, drugs, notifications, public healthcare system

\section{INTRODUCTION}

Pharmacovigilance of quality deviations is aimed at preventing problems related to the use of medicines (PRM) under inappropriate quality conditions. ${ }^{1,2}$ Visual inspection of medicines is a fundamental step in pharmaceutical care, whose objective is to contribute to the effectiveness and safety of pharmacotherapy offered by health systems. Because it does not require complex infrastructure or equipment and identifies a wide range of inadequacies to the parameters defined in the drug registration, ${ }^{3}$ the inspection should be encouraged. Reporting medication quality deviations (MQD) is relevant to health systems and contributes to actions of regulatory agencies. ${ }^{4}$ Between 2006 and 2013, the National Health Surveillance System (SNVS) received 44,054 notifications (about 3,300 technical complaints/year), which leads us to understand the need to promote studies in the area, notification and strengthen pharmacovigilance in Brazil. ${ }^{3,5}$.

The various professionals working in the Basic Health Care (ABS) of the Unified Health System (SUS) should develop surveillance of technical complaints and adverse events related to medicines, ${ }^{5}$ but this action still remains distant from daily pharmaceutical practice at this level of attention. $2,6-8$ Maintaining interface with several stages of the pharmaceutical care logistics cycle, pharmacovigilance stands out in the selection of medical products complying with the technical and scientific requirements, the acquisition of the medicines selected by maintaining the surveillance of the quality and safety required in the purchase notice and in the dispensing, as a last opportunity to check the quality before the patient's access to the medication. MQDs can also compromise adherence to drug therapy and programming supply of medicines in an institution. ${ }^{9}$

The high prevalence of the MQDs identified in studies evaluating PRM in a hospital environment evidences the importance of these reports., ${ }^{4,11}$ This study describes MQD at the primary and secondary health care levels, evaluating its financial impact and programming the pharmaceutical assistance of the public network of the third largest Brazilian municipality.

\section{METHOD}

Cross-sectional study on MQDs registered in the primary and secondary care units of the nine health districts of the Municipal Health Secretariat of Belo Horizonte (SMSA-BH), Minas Gerais. The network consists of 152 Basic Health Units (UBS), seven Emergency Care Units (UPA), eleven Reference Centers for Mental Health (Cersam), five Secondary Reference Units (URS), three Drug Dispensing Units (UDM) and nine District Pharmacies (FD). The supply of medicines is based on the Municipal Relation of Essential Medicines (Remume), composed of 270 medicines in 384 pharmaceutical presentations. ${ }^{12}$ Average monthly consumption (CMM) across the network was approximately 35 million pharmaceutical units in the year 2015, planned to serve an estimated population of 2.5 million.
1 Prefeitura de Belo Horizonte 2 Universidade Federal de Minas Gerais 3 Fundação Ezequiel Dias

Submitted: $5 / 7 / 18$

Resubmitted: $1 / 11 / 18$ Accepted: 24/11/18

How to cite this paper: Bitencourt CR, Pádua CAM, Drummond PLM, Perini E.

Pharmacovigilance of quality deviations in the public healthcare system. Rev Bras Farm Hosp Serv Saude, 9(4): 1-7,

2018.

Doi: 10.30968/rbfhss.2018.094.004

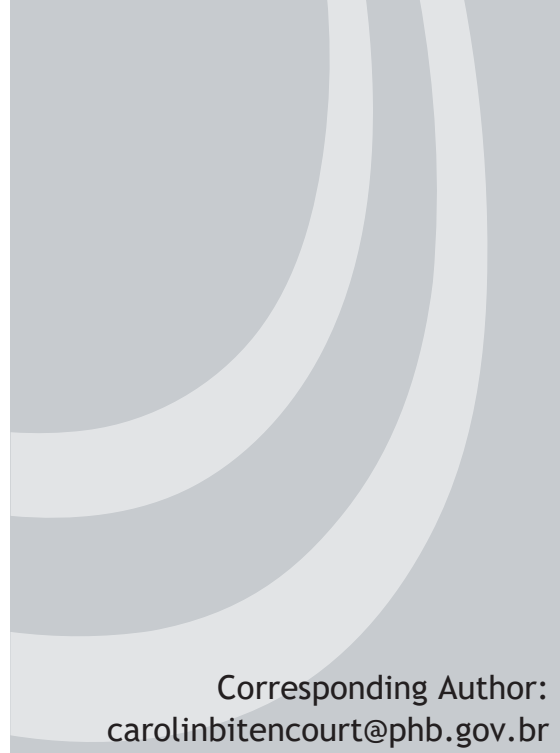


All MQD notifications registered between April and September 2016, involving pharmaceutical specialties standardized by the municipality were analyzed. This period coincides with the consolidation of the program implemented in the institution in January of the same year. Replies to the notifications were tracked until December 2016. Records with impairment of quality caused by the handling or transport of medicines were excluded.

The variables selected for the study were:

- Medication - Active ingredient, therapeutic class (ATC classification - Anatomical Therapeutic Chemical Classification - Level 3), ${ }^{13}$ pharmaceutical form, laboratory manufacturer, level of care where it is used (Remume). ${ }^{12}$

- Quality deviations - Classified into four groups: packaging integrity, packaging content, labeling and changes in the product. Each group was subdivided into types, according to the pharmaceutical form, based on similar classification proposed for the study of MQDs in hospitals. ${ }^{10,11}$ Given that the profile of drugs in primary and secondary care is different, a more specific classification was necessary, and its adequacy can be seen in Table 1 .

- Reporting unit - Health care facility (UBS, UPA, URS, Cersam, $\mathrm{UMD}, \mathrm{FD}$ ) and health district that registered the MQD.

- Impact on pharmaceutical care - Potential impact on the programming of pharmaceutical care, comparing the CMM with the number of units lost. The deviation representativeness was calculated considering the number of units lost divided by the total number of units purchased from the same lot. The percentages of representativity were grouped into bands for analysis (0.00-0.10\%, $0.11-0.50 \%, 0.51-1.00 \%, 1.01-2.00 \%,>2.00 \%$ ).
- Sanitary Health risk - Classification considering possible compromises for the drug, for the patient and for pharmaceutical assistance (Table 1):

- Class I - Higher risk; situations with a high probability that the use or exposure to a drug may lead to death, life threatening or permanent damage;

- Class II - Intermediate risk; situations in which the potential harm is temporary or reversible by drug treatment;

- Class III - Lower risk; situations with a low probability of causing adverse health consequences. ${ }^{14,15}$

- Potential financial cost - Expressed in reais and dollars, expresses the direct cost of the lost units of medicines and their proportion in relation to the total purchased, using the average unit cost obtained in the Integrated Inventory Management System (SIEST). The exchange rate was calculated based on the conversion of the data collection closing date $(\mathrm{U} \$ 1.00=\mathrm{R} \$ 3.24$, on $10 / 15 / 2016) .{ }^{16}$

- Supplier notifications - Proportion of the number of MQDs registered and notified to suppliers in relation to the total, classified by their outcomes: satisfactory resolution (units replaced), unsatisfactory (no return or refusal of supplier to investigate notification) or in progress (samples collected or first return).

- SNVS notifications - Proportion of the number of MQDs registered and reported in the Health Surveillance Notification System (Notivisa) in relation to the total, and the status of investigation of the same according to the system itself. ${ }^{17}$

Table 1 - Sanitary risk by groups and types of quality deviations observed in medicinal products. Belo Horizonte, April to September, 2016

\begin{tabular}{|c|c|c|}
\hline \multirow{2}{*}{ Sanitary risk } & \multicolumn{2}{|l|}{ Quality deviations } \\
\hline & Groups & Types \\
\hline \multirow{7}{*}{ I (high) } & \multirow[b]{2}{*}{ Change in medication } & Color change and other organoleptic changes. \\
\hline & & $\begin{array}{l}\text { Alteration in the powder for resuspension of injectable medicaments with precipitate formation or supernatant or volume after } \\
\text { reconstitution. }\end{array}$ \\
\hline & Package content & Primary, secondary or tertiary packaging containing another medical product. \\
\hline & Packaging integrity & Injectable drugs with leakage of unidentified origin or violated sealing. \\
\hline & Packaging integrity & $\begin{array}{l}\text { Packing of liquid or semi-solid medicaments broken or cracked, with leak in the lid, sealed or missing sealing. } \\
\text { Bottles or ampoules of broken injectable medicines. } \\
\text { Solid medicines with blister sealing violated or leak in the sealing of sachets. }\end{array}$ \\
\hline & Labeling & $\begin{array}{l}\text { Primary packaging with dirty, damaged or illegible labeling, missing labeling or lack of variable data (lot, manufacturing and } \\
\text { validity). }\end{array}$ \\
\hline & & Contents of incomplete secondary packaging. \\
\hline \multirow[t]{7}{*}{ II (intermediate) } & Package content & Contents of primary packaging of liquid, semi-solid and solid medicaments \\
\hline & & Solid medicines with tablet pressed out of the blister or more than one tablet per blister. \\
\hline & & Presence of a foreign body in primary packaging. \\
\hline & Change in medication & $\begin{array}{l}\text { Solid medicines presenting broken or crumpled tablet, open capsule or disintegrating. } \\
\text { Semisolid drugs with phase separation or change in consistency. } \\
\text { Alteration in the powder for resuspension of oral liquid medicaments with precipitate formation or supernatant or } \\
\text { incompatible volume after reconstitution. }\end{array}$ \\
\hline & & Medicines with compromised secondary or tertiary packaging. \\
\hline & Packaging integrity & Injectable medicines with an ampoule that will not break or crumble when breaking. \\
\hline & & Lack of accessories or devices for administration (bung, drops, measuring cup). \\
\hline \multirow[t]{4}{*}{ III (low) } & Labeling & $\begin{array}{l}\text { Secondary or tertiary packaging with dirty, damaged or illegible labeling, missing labeling or lack of variable data (lot, } \\
\text { manufacturing and validity). }\end{array}$ \\
\hline & & Content greater than that indicated on the label of primary, secondary or tertiary packaging. \\
\hline & Package content & Contents of incomplete tertiary package. \\
\hline & & Solid medicines with incomplete primary packaging (blister packs with empty blisters). \\
\hline
\end{tabular}


- Quality of information - Assessed according to completeness (complete/incomplete) and consistency (consistent/inconsistent) of notifications. Incomplete notifications containing blank fields in the Notivisa form were considered incomplete. ${ }^{8}$ The consistency of the information was evaluated through the cross-checking of data between the institution's internal records and Notivisa. Notifications containing data reported in only one of the records or with divergences between them were considered inconsistent. ${ }^{18}$

The descriptive analysis for the characterization of the study variables was performed by measures of central tendency (mean, median) and dispersion (standard deviation). The variation in the distribution of the number of MQD records (coefficient of variation) was analyzed throughout the study period at the level of significance $(\alpha=0.01)$. The linear relationship between CMM and number of registers per notifier was calculated using the Pearson coefficient, considering the level of significance of 0.05. Data was tabulated and analyzed in Microsoft Excel, version 2013.

The study is a partnership between SMSA-BH and the Center for the Study of the Medicine of the UFMG (Cemed) and was carried out after a letter of consent from the institution and waived submission to the Research Ethics Committee.

\section{RESULTS}

There were 276 notifications, five excluded from the study because they involved medicines deteriorated in handling or transportation. Of the 271 reports included (mean of $45.2 \pm 5.5 /$ month), some had more than one type of deviation, totaling 329 MQDs (mean of 1.21/record). The number of monthly notifications throughout the study presented coefficient of variation of 0.1218 , with no significant trends ( $\alpha=0.01)$.

A moderate positive relationship was observed between CMM and the number of notifications performed in different sanitary districts (correlation coefficient 0.51 ) (Table 1). All types of healthcare facilities reported at least once in the period, and the BHU (63.8\%) and the FD (30.6\%) accounted for about $95 \%$ of the same.

Table 1 - Percentage distribution of notifications of quality deviation and average monthly consumption per notifying health district. Belo Horizonte, April to September, 2016

\begin{tabular}{llll}
\hline \multirow{2}{*}{ Sanitary district } & $\mathbf{C M M}(\%)$ & \multicolumn{2}{l}{ Notifications } \\
\cline { 3 - 4 } & & $\mathbf{N}$ & $\%$ \\
\hline South Center & 6.0 & 9 & 3.3 \\
Venda Nova & 8.9 & 32 & 11.8 \\
Pampulha & 9.4 & 45 & 16.6 \\
Northwest & 10.8 & 31 & 11.4 \\
East & 11.0 & 16 & 5.9 \\
Northeast & 11.5 & 20 & 7.4 \\
North & 11.8 & 29 & 10.7 \\
Barreiro & 12.8 & 49 & 18.1 \\
West & 17.8 & 40 & 14.8 \\
Total & 100.0 & 271 & 100.0 \\
\hline
\end{tabular}

Source: Belo Horizonte City Health Department

$\mathrm{CMM}=$ average monthly consumption

Solid drugs accounted for $68.3 \%(n=186)$ and liquids $19.9 \%(n=54)$ of the notifications. Among the liquids, 55.6\% corresponded to injectable drugs. Only one record involved semisolids. MQDs occurred in 21.1\% $(n=83)$ of the standardized drugs in the network, and in $49(59.0 \%)$ there was recurrence. Of the notifications observed, $84.9 \%(n=230)$ involved drugs used at the primary, secondary and emergency care levels, and 41 were standardized exclusively for primary care.
The registered MQDs led to the destruction of 9,311 pharmaceutical units. The direct financial cost was R $\$ 994.82$ (US\$ 307.04), with an average of R\$ $11.99+/-28.37$ per unit, and a median of $\mathrm{R} \$ 3.69$. This represents about $0.005 \%$ of the total financial value of medicines handled in the nine health districts during the study. The notifications concluded with satisfactory resolution involved the replacement of $83.6 \%(n=7,786)$ of the lost units and the reimbursement of $36.2 \%(\mathrm{R} \$ 360.16)$ of the financial loss resulting from the destruction of these drugs.

Most MQDs $(64.9 \%, \mathrm{n}=176)$ compromised up to $0.01 \%$ of the total units purchased from the same batch of the drug, $74(27.3 \%)$ compromised from $0.11 \%$ to $0.50 \%$ of the batch and $25(9.2 \%)$ compromised from $0.51 \%$ to $1.0 \%$. Only two notifications compromised from $1.01 \%$ to $2.0 \%$ of the units purchased and four committed more than $2.0 \%$ of the purchased lot (from $4.0 \%$ to $8.3 \%$ ).

The most frequent group of MQD was "Packaging Content" (47\%, $\mathrm{n}=154)$, followed by "Packaging Integrity" (26\%, n=85), "Medication Changes" and "Labeling" (5\%, n=17). Only deviations classified as "Packaging Integrity" occurred more frequently in liquid drugs $(44.7 \%, \mathrm{n}=38)$, of which 23 were registered in drugs produced by two pharmaceutical laboratories (Figure 1). In the other MQD groups, solid drugs predominated.

Most of the records were classified as medium $(69 \%, n=187)$ and low $(27.3 \%, \mathrm{n}=74)$. However, ten $(3.7 \%)$ reports were classified in the high sanitary risk class (risk class I), with $70 \%$ of these records referring to the integrity of the package. In 17 records, the integrity of the packaging also caused problems in the content of the drug, especially in liquid medicines $(\mathrm{n}=13)$ (Table 2).

Table 2 - Frequency of reported quality deviations, according to ATC classification of drugs and Sanitary Risk. Belo Horizonte, April to September, 2016

\begin{tabular}{|c|c|c|c|c|}
\hline \multirow{2}{*}{$\begin{array}{l}\text { ATC Classification of Medicinal } \\
\text { Products with Quality Deviation }\end{array}$} & \multirow{2}{*}{$\begin{array}{l}\text { Registered } \\
\text { notifications } \\
(\mathrm{n})\end{array}$} & \multicolumn{3}{|c|}{ Sanitary risk } \\
\hline & & High & Intermediate & Low \\
\hline Anti-infectives for systemic use (J) & 57 & 2 & 40 & 15 \\
\hline Nervous system $(\mathrm{N})$ & 55 & 1 & 40 & 14 \\
\hline Food tract and metabolism (A) & 50 & 1 & 32 & 17 \\
\hline Cardiovascular system (C) & 38 & 2 & 18 & 18 \\
\hline Respiratory system (R) & 20 & - & 13 & 7 \\
\hline Blood and hematopoietic organs (B) & 18 & 4 & 14 & - \\
\hline $\begin{array}{l}\text { Genitourinary system and sex } \\
\text { hormones }(G)\end{array}$ & 13 & - & 11 & 2 \\
\hline Antiparasitic products $(\mathrm{P})$ & 12 & - & 12 & - \\
\hline Muscle skeletal system (M) & 6 & - & 5 & 1 \\
\hline $\begin{array}{l}\text { Hormone preparations for systemic } \\
\text { use and insulins }(\mathrm{H})\end{array}$ & 2 & - & 2 & - \\
\hline Total & 271 & 10 & 187 & 74 \\
\hline
\end{tabular}

MQDs referred to ten different pharmacological classes. Anti-infectives for systemic use, drugs that work in the Nervous System and in the Food Tract were the most frequent (Table 2).About half of the drugs were supplied to the municipal health network by distribution companies $(41.0 \%, \mathrm{n}=111)$ or directly by the manufacturing laboratories $(8.1 \%, \mathrm{n}=22)$. The other half, distributed to the district pharmacies by the central warehouse of SMSA-BH $(50.9 \%, n=138)$, was acquired by the three spheres of government: SMSA$\mathrm{BH}$ and the State Department of Health (SES) acquired 45\% (61 and 64, respectively) and the Ministry of Health provided $10 \%(n=13)$.

All registered MQDs were notified to suppliers and 64.6\% $(n=175)$ of notifications had some return: 115 notifications had the units replaced in an average time period of 67.7 days, samples of 30 notifications were collected for analysis and 28 notifications were either reset or had contact 
Figure 1 - Distribution of quality deviations ( $\mathrm{n}=329)$ observed in the notifications, by group and type. Belo Horizonte, April to September, 2016
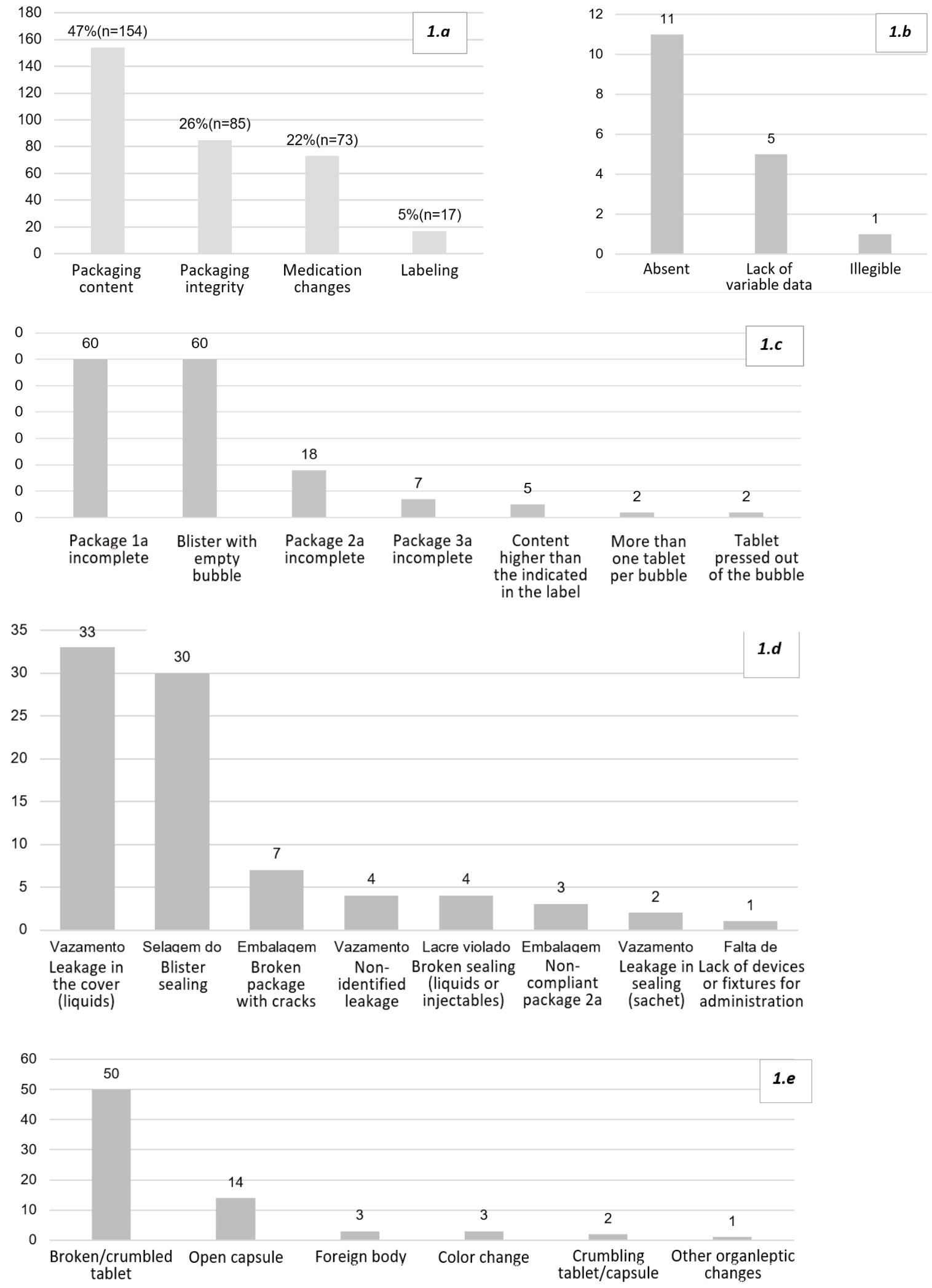

Caption:

1.a - Percentage distribution of quality deviations per group.

1.b - "Labeling" group $(n=17)$ : number of quality deviations by type.

1.c - "Packing content" group $(\mathrm{n}=154)$ : number of quality deviations by type.

1.d - "Packaging integrity" group $(n=84)$ : number of quality deviations by type.

1.e - "Changes in Medication" group $(n=73)$ : number of quality deviations by type. 
via e-mail or telephone for trading until the closing date of the data collection. The mean sample collection time was 48.5 days. The agility to return to the notification was greater for the manufacturing laboratory (average term of 39 days) when compared to the other suppliers. However, laboratories represented the second highest rate of non-return (68.2\%). The highest average return period was obtained for medicines provided by SES-MG through the Central Warehouse (average term of 75 days). SESMG was responsible for the best rate of return of notifications addressed to it $(73.4 \%)$. The highest proportion of non-return notifications was found for medicines provided by the Ministry of Health through the Central Warehouse $(92.3 \%, \mathrm{n}=12)$.

Drugs with at least one diversion record were produced by 38 different pharmaceutical laboratories. Recidivism occurred in products of five of them, totaling $40 \%$ of total notifications. All records were notified to the health authority through the Notivisa portal. Only $2.6 \%(n=7)$ had the status "In grouping" changed. Six notifications were in the "Investigation" stage by SNVS and one "Under review". The records in Notivisa had an incompleteness rate of $34.3 \%(n=93)$. Some records presented more than one blank field, the main ones being: problem identification address $(n=52)$, date of manufacture of medication $(n=25)$, place of purchase of medication $(n=22)$ and presentation=20). The inconsistency between the information recorded in Notivisa and in the institution's own form was detected in 49 notifications (18.1\%). In all cases, an active search was performed to confirm divergent $(n=41)$ or incomplete $(n=8)$ data and the records were included in the study.

\section{DISCUSSION}

Our findings demonstrated a significant number of MQD records in primary and secondary care of the public healthcare system in Belo Horizonte. The comparative evaluation of the number of notifications in the $\mathrm{ABS}$ environment is hampered by the fact that similar studies occur in a hospital environment, a quite different universe, from a network of services with various levels of complexity. Nevertheless, the number of reports we observe is high in relation to other studies involving MQD.(4,11,19-21) As this is a recent program, and because we have studied for a short time, the assessment of variations or trends over the period is hampered. There is an expected increase in notifications during maturation of the program, a fact reported in a distinct environment, with an increasing trend in the number of notifications over three years attributed by the authors to the consolidation of the pharmacovigilance program. ${ }^{19}$ This trend should be constantly assessed. While it is desirable to grow notifications as a result of the maturation of the program, it is also expected that stabilization or even a decrease will signal the achievement of improvements in the procurement process and the commercial relationship between the health system and the market of pharmaceutical products.

Between 2006 and 2014, the Municipal Health Departments of the entire country notified 1,784 technical complaints in Notivisa (198.2 notifications/year). Underreporting, a characteristic problem of spontaneous reporting programs, may be at the root of this low number of notifications over the six months of the study, which reinforces the importance of strengthening pharmacovigilance programs in all care services the health. ${ }^{5,22}$

The organization of the municipal health network around ABS agrees with the observation of greater participation of the BHUs in the notification process. Intermediaries in distribution, district pharmacies play an important role in notifications (second largest notifier) but are limited by the fact that many drugs are distributed in sealed packages, making it difficult to identify MQD. The organization of the system around ABS also accounts for the higher proportion of MQD in solid drugs. Most of the medicines dispensed in these units are chronic use, in the form of tablets or capsules, different from the hospital environment where the highest consumption and most of the MQDs involve injectable drugs. ${ }^{10}$ On the other hand, the main therapeutic classes with observed MQDs corroborate with other evidences. ${ }^{4}$ There are two classes with regulation that is differentiated by legislation that establishes strict criteria for dispensing, with retention of medical prescription, whose continuity of treatment is determinant of pharmacotherapeutic success, whose MQDs identified may cause therapeutic failure.

The most frequent MQD, "Package content", also observed in other studies, was characterized by the predominance of "incomplete blister" or "empty bubble", in proportion to the studies performed in hospitals. $4,10,20$ This is easily understood by the profile of consumption of medicines characteristic of health services. Although apparently of low risk, these problems may compromise therapeutic effectiveness by facilitating discontinuation of treatment due to insufficient supply of the drug. Already the problems in the integrity of the packaging can cause contamination of the medicine and impair its stability, impacting on the quality and the safety, reason why they represent greater sanitary risk.

Changes that directly affect the drug are related to therapeutic ineffectiveness, adverse events or toxicity. The main alteration of this type is related to the friability of tablets (divided, crumbled or disintegrating) or open capsules, followed by alteration of color of the medicine and presence of foreign body. This reality is also different from the hospital environment and, in the case of the latter two, in a proportion inferior to that reported by other authors. ${ }^{4,11,21,22}$

There is an important relationship between technical complaints and medication errors by compromising the correct identification of the drug $^{21}$, Descrição das notificações de queixas técnicas de medicamentos recebidas pela farmacovigilância do Hospital de Clínicas de Porto Alegre ${ }^{21}$ The absence of the label is more easily identified than the illegibility or absence of variable data (batch, manufacturing and validity), and the latter were in fact reported less than other studies. ${ }^{10,11,20}$

Most ABS medicines are purchased at a low unit cost due to the volume purchased, the drug profile and the bidding mode. For this reason, even with the loss of large volume of pharmaceutical units, the direct financial cost of MQDs was not high. However, indirect costs not evaluated in this study should be considered by health institutions. These include reverse logistics for sample collection, cost for replacement, rework, and treatment of MRP eventually caused by diversion, among others. Given that the number of units lost was lower than the daily consumption of the municipality, for all the products involved in the notifications, we can conclude that the MQDs are not significantly impacting the scheduling and supply in the SMSA-BH. Because we do not yet have an assessment of the level of underreporting, overhead and the impact of these events on patient care, we believe that this evaluation may change throughout the maturation process of pharmacovigilance actions, reinforcing the recommendation of systematic monitoring of the data generated in the program.

Recidivism of MQD was observed for the same drug, for different batches and sometimes a manufacturer had problems in more than one drug. It is thus noted that this is not a specific problem, but a diffuse reality involving the production process and Good Manufacturing Practices. ${ }^{17}$ It also reinforces the need for more efficient monitoring and intervention by regulatory bodies on the production sector and for discussion of the possibilities for cooperation between pharmacovigilance and health actions. We observed that of the five laboratories most cited in the records of MQD three were sanitary measures of the SNVS, during the same period, and underwent intervention in the manufacture or commercialization. ${ }^{24}$ Although the purchase notice includes requirements for suitability for the service, the degree of quality sought and requirements such as the obligation to submit a quality report with the invoice, the results show that the quality declared in the reports does not always match the quality found in the drugs purchased. ${ }^{1}$

Differences in the treatment of notifications addressed to suppliers regarding the deadline and the resolution of the return were observed. The research flow begins with the evidence of MQD through sample collection and, subsequently, its replacement, which justifies a longer period for the second step, when compared to the first one. The refusal to replace units with MQD from two notifications whose sample had been discarded shows real difficulties in the business relationship. Among the suppliers, the greater agility of the manufacturing laboratories that sold directly to SMSA$\mathrm{BH}$ in returning the notifications is understandable by the inexistence of intermediates in the distribution chain of the medicines. The proportion of notifications with satisfactory resolution was lower than that found in 
similar studies, which reinforces that pharmacovigilance is a viable tool for managing resources and combating waste, including allowing the creation of a database that subsidizes the evaluation of suppliers. ${ }^{9,20,21,25}$

We found a small proportion of notifications investigated by SNVS, lower than studies in a hospital environment. The slowness of this investigation, which may eventually require inspections in loco or laboratory analyzes, is a discouraging factor for notifiers. ${ }^{5,6,15,21}$ The Agency uses two criteria to trigger this process of analysis: sanitary risk and recurrence of notifications, which reinforces the importance of systematic notification of MQD, regardless of the sanitary risk attributed. ${ }^{17}$

There is a direct relationship between the quality of MQD records and the process of analyzing notifications. Incomplete or inconsistent information may omit essential information and jeopardize SNVS investigation and substitution by suppliers. The incompleteness can be attributed to the lack of clarity as to the terminologies used to define what is being notified. ${ }^{26}$ In this study, about a third of the notifications were made at Notivisa, and it was not possible to determine if this problem caused the investigation to be compromised due to the agency's lack of positioning. For the incomplete fields, no relation with the difficulty in filling was evidenced. Of the four most incomplete fields, one is free to fill in and the others are multiple fill. At this point, the non-mandatory filling of fields considered essential by the SNVS seems to contradict us, since it facilitates the omission of this information. Failure to fill in some variables may reflect the lack of care or the low importance given by the notifier to the collection instrument, reinforcing the need to promote training actions, improvement of collection instruments and definition of concepts and information flow.

Another important aspect of the quality of the notification is the consistency between the detected MQD and the information recorded in the SNVS and with the suppliers. Problems of information quality indicate the need for ongoing training and to establish process indicators that indicate the shortcomings of the pharmacovigilance program. By ensuring reliable registration, the information recorded can support decisions within the institution and in the regulatory environment more reliably. 5,722,23,25

Much of the knowledge about MQD has been generated from evaluations in the hospital environment and little is known about its importance in the context of primary and secondary health care. In spite of the short-term evaluation, the lack of evaluation of the level of underreporting, the indirect costs and the impact of MQDs on care, we believe that our study may contribute to raising awareness of the importance of MQDs and strengthening pharmacovigilance actions in care primary and secondary to health.

\section{CONCLUSION}

The proposed MQD and sanitary risk classifications were adequate for the profile of medicines used in the primary and secondary care of the pubic network. Pharmacovigilance was an important tool in the prevention of harm to the patient, since it allowed the identification and segregation of MQDs, preventing their consumption. The findings regarding the number of records and the recidivism observed demonstrate the importance of this segregation.

Despite the low direct financial cost, the tool is also relevant in order to compensate for the damage caused and to prevent indirect costs arising from the use of medicines with a quality deviation.

The difficulty in obtaining satisfactory resolution of the notifications suggests the need for a more complex quality monitoring by the manufacturing laboratories, as well as the more frequent SNVS tax analyzes in the post-marketing phase of the medicines.

Inaddition to therelevance of the findings, thelack of pharmacovigilance research at the levels analyzed are important arguments to encourage the development of pharmacovigilance activities with pharmaceutical assistance throughout the drug distribution chain at all levels of care. The minimization of impacts and the provision of safe and effective medicines to patients justify all actions and investments.

\section{Funding}

This study had no funding.

\section{Contributors}

CRB participated in all stages of the work (project design and data analysis and interpretation, article writing and critical review of the intellectual content, final approval of the version to be published, responsibility for all work information, ensuring accuracy and integrity of any part of the work); CAMP participated in the relevant critical review of the intellectual content and final approval of the version to be published; PLMD participated in the relevant critical review of the intellectual content and final approval of the version to be published and EP participated in the relevant critical review of the intellectual content and final approval of the version to be published.

\section{Conflict of Interest}

The authors declare that there is no conflict of interest for the work.

\section{REFERÊNCIA BIBLIOGRÁFICAS}

1. Luiza VL, de Castro CGSO, Nunes JM. Aquisição de medicamentos no setor público: o binômio qualidade-custo Pharmaceutical procurement by the public sector: the quality/cost relationship. Cad Saúde Pública. 1999;15(4):769-76.

2. Salviano LHMS, Luiza VL, Ponciano AMS. Percepção e condutas de profissionais da Estratégia Saúde da Família acerca de reações adversas a medicamentos. Epidemiologia e Serviços de Saúde. $2011 ; 20(1): 47-56$.

3. Agência Nacional de Vigilância Sanitária. NOTIVISA - Sistema de Notificações em Vigilância Sanitária; 2009 Disponível em: < http:// www.anvisa.gov.br/hotsite/notivisa/apresenta.htm>. Acesso em 01 set. 2015 .

4. Lima PFd, Cavassini ACM, Silva FAT, Kron MR, Gonçalves SF, Spadotto A, et al. Queixas técnicas e eventos adversos a medicamentos notificados em um hospital sentinela do interior de São Paulo, 20092010. Epidemiologia e Serviços de Saúde. 2013;22(4):679-86.

5. Brasil. Agência Nacional de Vigilância Sanitária. Diretrizes Nacionais para a Vigilância de Eventos Adversos e Queixas Técnicas de Produtos sob Vigilância Sanitária 2016, 10p. Disponível em: < http:// portal.anvisa.gov.br/wps/content/Anvisa+Portal/Anvisa/Pos++Comercializacao+-+Pos+-+Uso/Vigipos/Assunto+de+Interesse/ Diretrizes+Nacionais+de+VIGIPOS>. Acesso em: 01 set. 2015.

6. Dresch C. Farmacovigilância e a atenção primária à saúde: diálogo possível e necessário. Rev APS. 2006;9(1):73-82.

7. Prakasam A, Nidamanuri A, Kumar S. Knowledge, perception and practice of pharmacovigilance among community pharmacists in South India. Pharm Pract (Granada). 2012;10(4):222-6.

8. Romero DE, Cunha CB. Avaliação da qualidade das variáveis sócioeconômicas e demográficas dos óbitos de crianças menores de um ano registrados no Sistema de Informações sobre Mortalidade do Brasil (1996/2001). Cad Saúde Pública. 2006;22(3):673-84.

9. Rissi NMN. Gestão de desvios técnicos no recebimento de medicamentos na Central de Abastecimento Farmacêutico. 2011.

10. Visacri MB, de Souza CM, Sato CM, Granja S, de Marialva M, Mazzola PG, et al. Adverse Drug Reactions and quality deviations monitored by spontaneous reports. Saudi Pharm J. 2015;23(2):130-7.

11. Caon S; Feiden IR; Santos MA. Desvios De qualidade de medicamentos em ambiente hospitalar: identificação e avaliação das ocorrências. Rev Bras Farm Hosp Serv Saúde São Paulo v. 
$2012 ; 3(1): 23-6$

12. Belo Horizonte, Prefeitura Municipal de. Portaria SMSA/SUS-BH n.0094/2014. Divulga a Relação de Medicamentos Municipais REMUME, Diário Oficial do Município. 30 junho de 2014.

13. World Health Organization. Anatomical Therapeutic Chemical Classification. Disponível em: <http://www.anvisa.gov.br/datavisa/ Substancia/ATC.htm>. Acesso em: 18 nov. 2016.

14. Brasil. Agência Nacional de Vigilância Sanitária. Resolução RDC n.55 de 17 de março de 2005. Diário Oficial da União. 21 de março de 2005 .

15. Capucho H, Hospitalar F. Processos Investigativos em Farmacovigilância. Pharmacia Brasileira, Brasília. 2008;67:1-12.

16. Brasil. Banco Central do. Câmbios e Capitais Internacionais. Disponível em: <http://www.bcb.gov.br/rex/sml/3-1-taxa.asp>. Acesso em: 15 out. 2016.

17. Brasil. Agência Nacional de Vigilância Sanitária. Diretrizes para investigação de queixas técnicas de medicamentos e aplicação de processo administrativo sanitário. In: Sanitária ANdV, editor. Brasília2010.p.90p.

18. Pinto IV, Ramos DN, Costa MCE, Ferreira CBT, Rebelo MS. Completude e consistência dos dados dos registros hospitalares de câncer no Brasil. Cad Saúde Coletiva. 2012;20(1):113-20.

19. Bezerra ALQ, Silva AEBC, Branquinho NCSS, Paranaguá TTB. Análise de queixas técnicas e eventos adversos notificados em um hospital sentinela. Rev enferm UERJ. 2009;17(4):467-72.

20. Universidade Federal do Rio de Janeiro. Gerência de Risco do Hospital Universitário Clementino Fraga Filho. Queixas Técnicas em Farmacoviligância - Como lidar com elas?. 2010.

21. Santos L, Oliveira FR, Martinbiancho J, Jacoby T, Mahmud SDP, Fin MDC, et al. Descrição das notificações de queixas técnicas de medicamentos recebidas pela farmacovigilância do Hospital de Clínicas de Porto Alegre. Clinical \&amp; Biomedical Research. 2012;32(4).

22. Organização Mundial da Saúde. Grupo de Trabalho em Farmacovigilância. Boas Práticas de Farmacovigilância para as Américas. 2011.85p.

23. Brasil. Agência Nacional de Vigilância Sanitária. Produtos Irregulares Disponível em: <http://portal.anvisa.gov.br/produtosirregulares\#/>. Acesso em: 9 nov. 2016.

24. Gil RB, Chaves LDP, Laus AM. Gerenciamento de recursos materiais com enfoque na queixa técnica. Revista Eletrônica de Enfermagem. 2015;17(1):100-7.

25. Silva RS, Oliveira CM, Ferreira DKS, Bonfim CV. Avaliação da completitude das variáveis do Sistema de Informações sobre Nascidos Vivos-Sinasc-nos Estados da região Nordeste do Brasil, 2000 e 2009. Epidemiologia e Serviços de Saúde. 2013;22(2):347-52. 